\title{
A platform for customization and publication of open educational games
}

\author{
Delano M. Beder \\ Joice L. Otsuka \\ Departmemt of Computing (DC) - Laboratory of Learning Objects (LOA) \\ Federal University of São Carlos (UFSCar) \\ São Carlos - SP, Brazil \\ e-mail: \{delano,joice $\} @$ ufscar.br
}

\begin{abstract}
In a complex and expensive area, such as the development of educational games, solutions that advocate the collaboration, sharing, and reuse are important in order to make possible the area advance and also encourage that these educational resources can be effectively used by their target audience: teachers and students. This article presents the REMAR ${ }^{1}$ platform which aims to make easier the creation and sharing of open educational games. Besides, this article presents the initial results obtained in the pilot tests involving the proposed platform usage by students, teachers and game developers.
\end{abstract}

Keywords: open educational resources, educational games.

\section{Introduction}

According to James Paul Gee (2007), learning is intrinsic to good games, considering that in these we are constantly challenged to overcome our limits and to develop new skills. As a result, using games encourage us to learn to achieve the proposed goals, and thus we develop skills as strategies to win the game, take control, make decisions and solve problems for the pleasure of overcoming the challenges that are proposed. The good games are able to take the player quickly to a Flow State, defined by the psychologist Mihaly Csikszentmihalyi (1991) as a state of intense concentration in which the person is totally immersed in what he is doing, characterized by a feeling of total involvement and success, in which everything that is done seems to be extremely pleasurable.

Games are often aligned with more modern learning theories, which presuppose dynamic, active, context-based, problem-based learning (CONNOLLY et al., 2012). And these are more aligned with the cognitive styles of the nowadays students, which were born immersed in a digital and connected world (PRENSKY, 2000).

However, the educational games design process is complex and requires special attention because a harmonious combination of educational and entertainment aspects is essential in order to effectively promote playful learning experiences. In this way, it is important to look up for more sustainable solutions that favor sharing, adaptation, and more effective reuse of these resources. It is also essential to search out solutions that allow a major role for teachers in the creation of games, so that they can appropriate these resources with autonomy and safety.

\footnotetext{
${ }^{1}$ REMAR is acronym for Recursos Educacionais Multiplataforma Abertos na Rede (Open Multiplatform Educational Resources).
} 
VIII Congresso Brasileiro de Informática na Educação (CBIE 2019)

Anais do XXX Simpósio Brasileiro de Informática na Educação (SBIE 2019)

It is possible to emphasize among the main requirements of an educational game:

- To balance the ludic and educational elements in the game (KLOPFER; OSTERWEIL; SALEN, 2009). That is, educational and fun aspects should be considered together, neither of which should be prioritized, aiming at a game that keeps both sides in balance and promotes playful experiences of learning;

- To associate the educational aims to the game goals by integrating educational aims with mechanics, narrative, aesthetics (KIILI et al., 2012). That is, educational objectives must permeate the main elements of the game in order to generate more attractive experiences;

- To maintain the challenges and abilities balanced, keeping the player engaged, acting within the limits of her/his competence. The challenges must increase gradually, as the player develops new skills. According to James Paul Gee (2007), good games are able to keep the player in a state of "pleasantly frustrating".

As an educational resource, it is also important that games be designed adopting an inclusive design approach, that is, taking into consideration the diversity and aiming to guarantee the access and involvement of all, as far as possible. As a result, inclusive design should consider aspects such as accessibility for people with disabilities, access in locations with low or no connectivity, access to hardware with different configuration profiles, different ages and idioms (STEPHANDI, 2018). In particular, we advocate the following requirements:

- To design games that promote experiences equivalent to people with some type of disability. That is, the game should be designed to present alternative or complementary ways of perception of the game world, interaction and feedback that respect different limitations of users;

- To design games that can be accessed through different devices (desktops, smartphones, tablets), with alternative versions considering different platforms and connectivity conditions.

Overcoming the challenges of developing a good educational game is not a trivial task. The development of games that promote effective playful learning experiences and take into account an inclusive design approach requires time and resources, in general, far beyond those available in most game development projects. In this context, we believe that initiatives that promote greater collaboration of the community of educational game development, in the sense of developing games as open educational resources, which can be adapted and reused in different contexts, can contribute significantly to the advance of this area.

In this article we present the REMAR platform, developed aiming contributing to the development of games as open educational resources, looking up to provide solutions that can be better reused. This remainder of this text is organized as follows. Section 2 presents the terminology adopted in this work related to open educational resources/games. Section 3 presents the proposed platform. Section 4 shortly explains a comparison with related work. Section 5 presents the initial results obtained in the pilot tests. Finally, Section 6 summarizes the conclusions of this work. 
VIII Congresso Brasileiro de Informática na Educação (CBIE 2019)

Anais do XXX Simpósio Brasileiro de Informática na Educação (SBIE 2019)

\section{Open Educational Games}

According to David Wiley (2019), there are five reuse ways that should be allowed in an open educational resource (OER), known as 5R:

- Retain - the right to make, own, and control copies of the content;

- Reuse - the right to use the content in a wide range of ways (e.g., in a class, in a study group);

- Revise - the right to adapt, adjust, modify, or alter the content itself (e.g., translate the content into another language);

- Remix - the right to combine the original or revised content with other open content to create something new (e.g., incorporate the content into a mashup);

- Redistribute - the right to share copies of the original content, your revisions, or your remixes with others (e.g., give a copy of the content to a friend).

However, although a lot of resources are available under open licenses, many of them do not allow all forms of reuse cited by Wiley (2019) because they are available in non-editable formats (pdf, flash, exe), making it difficult to adapt. For an effective reuse of any resource, adaptations and/or customizations are usually necessary due the adjustment to the educational goals of each teacher. Ideally, such revisions should be able to be carried out directly by the teacher, allowing greater adaptation, appropriation and reuse safety. In this way, in the context of more complex development resources such as the educational games, it is not enough to license them under open licenses. It is necessary to propose solutions to make easier and simplify the adaptation and reuse of these resources.

Hence, some requirements that must be met in order for an OER to actually contemplate the 5Rs:

1. It must be available under open license for retention, reuse, redistribution, remix, review;

2. It must be produced using open technologies that favor revision/customization. And must be available in editable formats;

3. It must be designed for reuse and evolution. In this way, it must be modular and allow easy exchange of components (image, sounds and content files);

4. It must be easily reviewed/customized directly by teachers, so that they can participate directly in the construction of their resources, with autonomy and safety.

\section{The Proposed REMAR Platform}

As mentioned, the effective reuse of an open educational game involves concerns that go beyond making it available under less restrictive licenses, such as Creative Commons, since often these resources, although open, are made available in formats that do not favor their adaptation (non-editable formats or dependent on proprietary tools).

In this way, the revision/customization of these resources should be possible at different levels for different user profiles: (a) OER developers, who should have access to source code and OER components, being able to adapt them to new contexts and usage requirements; (b) educators from different areas, who should have access to a set of tools that facilitate the adaptation of these resources to their needs.

Besides, it is crucial to take into consideration different alternatives for the distribution of these resources to students. It is possible to highlight the following alternative 
platforms: (i) mobile, allowing access from any location, at any time through mobile devices; (ii) web, so that it can be accessed from any device connected to the Internet through a browser; (iii) desktop, so that it can be accessed through a desktop computer even without Internet access (offline). For the mobile and desktop versions it is considered important to synchronize with a resource provider (server), to send information about the game usage that can be analyzed by the teacher through analytical tools.

Regarding the reuse, it is important that this concern should be considered from the choice of open technological solutions to support the game development, the code structuring in order to favor reuse, the availability of resources with less restrictive licenses and the availability of tools that enable customization of content by non-developer users.

The REMAR platform was proposed and developed aiming to offer a solution to support and extend the reuse of open educational games, providing support for: (a) publication of customizable and open educational game models licensed under Creative Commons. In the context of the REMAR platform, a game model consists of a workflow designed to guide teachers in the customization activities; (b) customization of games directly by teachers, based on available educational game models, according to their needs and without the need for specific programming knowledge; (c) generation of customized instances of games for different platforms (web, desktop and mobile); (d) monitoring student progress during the educational games usage; and (e) integration with digital repositories for the publication and search of customization items.

In this way, the proposed solution has as its target audience three user profiles: (i) educational game developers, who publish open customizable game models; (ii) teachers, who create custom instances from the customizable game models; (iii) students, who access the custom games. The features related to each user profile as well as the REMAR platform architecture are presented in more detail in the following subsections.

\subsection{Architecture of the REMAR Platform}

The REMAR platform was developed following a modular architecture and using the Grails framework ${ }^{2}$ which is based on the Model-View-Controller (MVC) architectural pattern, adopts the Groovy language, runs on the Virtual Java Machine (JVM) and aims high productivity in web application development.

An overview of the architecture of the REMAR platform is presented in Figure 1. In the module, called Core, lies the functions that control the users' access and the custom games publication. In the context of the REMAR platform, each game model is implemented by a distinct web application in which the source code of the game and the game customization activities are found. In this context, a development team that intends to produce a new game model for the platform should develop, using Grails (or compatible technology), a web application responsible for the game's customization activities.

In the context of the REMAR platform, it is argued that the customizable games are modular in such a way that the customization points (that is, parts that can be customized in the game) should be easily delimited. In this sense, the customization points must be linked to different files, present in the game source code, which during the cus-

\footnotetext{
${ }^{2}$ For more details about the Grails framework, visit <https://grails.org.>
} 
VIII Congresso Brasileiro de Informática na Educação (CBIE 2019)

Anais do XXX Simpósio Brasileiro de Informática na Educação (SBIE 2019)

Figure 1. Architecture of the REMAR Platform

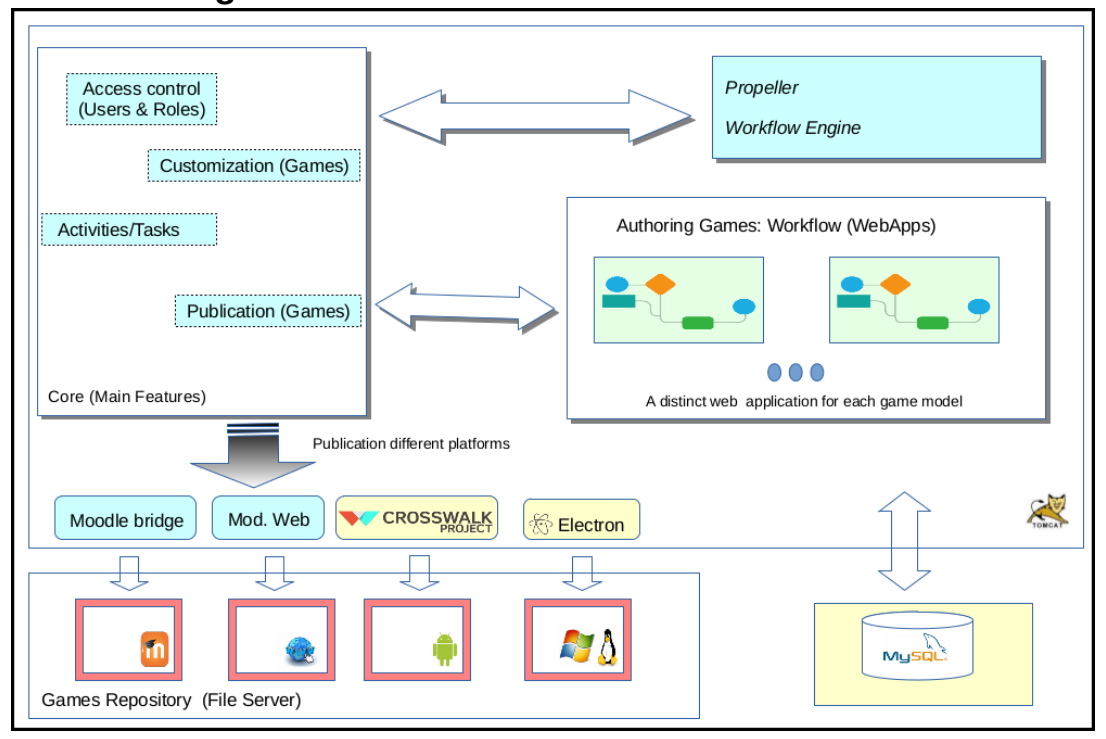

tomization process are overwritten with the custom content. Among the possible customization points, we can mention: (i) XML or JSON files that contain a set of questions for quizzes in a game; (ii) image files (PNG, JPEG, etc.) and so on. In this way, the customization workflow (defined by the workflow.json file) consists of several tasks, which have one or more outputs. The outputs represent the files that are replaced with the custom content. Tasks are implemented as MVC controllers and are in charge of execution of the planned customization activities in a game model.

In order to integrate the Core module with the modules responsible for the customization of games (game models) is utilized the workflow engine Propeller (developed by the REMAR platform team) which is responsible for automating, through the processing of the workflow.json file, the customization activities inherent to each game model. Finally, the REMAR platform ${ }^{3}$ is deployed on a Tomcat web server and currently supports the integration of games developed in HTML5 or Unity. The Crosswalk and Electron tools are employed to make it possible to publish HTML5 games for different platforms (mobile, desktop, etc.). In the case of games developed using Unity (or other tecnology), the game development team is in charge of providing the game code compiled for the different platforms (incorporated inside the game model).

\subsection{REMAR Platform: Developer Features}

The following features are available for the developer user profile:

1. Support for publishing customizable game models. A game model, to be published on the REMAR platform, must be compiled into a war ${ }^{4}$ file that contains a web application in which the source code of the game and the game customization activities are found (for example, the aforementioned workflow.json file).

\footnotetext{
${ }^{3}$ The REMAR platform is available at: <http://remar.rnp.br>.

${ }^{4}$ War file (Web application ARchive) is a file used to distribute a collection of resources that together constitute a web application.
} 
VIII Congresso Brasileiro de Informática na Educação (CBIE 2019)

Anais do XXX Simpósio Brasileiro de Informática na Educação (SBIE 2019)

2. Support for choosing the Creative Commons license for the customizable game model. In order to promote the culture of open license and the effective reuse of open educational resources, the REMAR platform restricts the choice to two modalities of the Creative Commons license: Creative Commons Attribution-ShareAlike (CC BY-SA 4.0) and Creative Commons AttributionNonCommercial-ShareAlike (CC BY-NC-SA 4.0).

\subsection{REMAR Platform: Teacher Features}

The following features are available for the teacher user profile:

1. Customization of educational games. Available game models can be customized through workflows created to guide teachers in the customization activities. Currently there are fifteen game models available on the platform. For brevity, this section presents just an example of an available customizable game model - the Cherlóqui Investigações de Acasos (CIA). In this game, the player must help the detective Cherlóqui Rolmes to unravel the mysteries when completing phrases presented as clues. Phrases can be completed with words present in a challenging word search puzzle. The game has the following customization items: (a) the cases to be investigated (challenging question) and (b) the clues (phrases indicating the gaps/words that will be presented in the word search puzzle). An example of CIA game model customization (cases and clues) can be observed in Figures 2(a) and 2(b). Each case can have 5 clues (sentences with word gaps in the word search puzzle) and a final challenge.

Figure 2. Cherlóqui Investigações de Acasos model

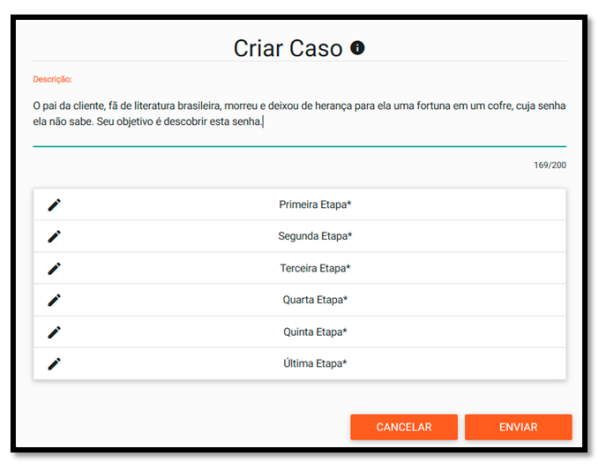

(a) Case customization

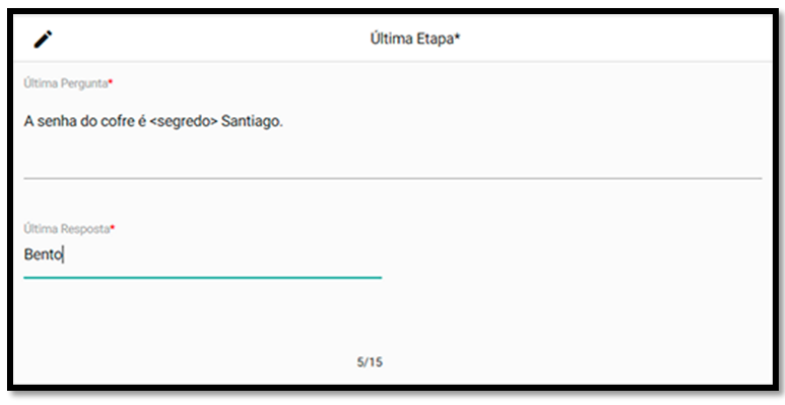

(b) Customization of the final challenge of a case

Source: Image capture from the REMAR platform (CC BY-SA 4.0)

2. Custom game instances generation for different platforms. The games customized by the teachers are generated for different hardware and software platforms: (i) Web (access through browsers in desktop computers, Tablets and Smartphones); (ii) Desktop-offline (can be used offline on computers running Windows, Linux or Mac operating systems); (iii) Mobile-offline (can be used offline on Tablets or Smartphones with the Android system). An example of custom game of the CIA model can be observed in Figure 3(a).

3. Publication and search of customization items in digital repositories. In order to promote the sharing of customization items as open educational resources (OER), 
VIII Congresso Brasileiro de Informática na Educação (CBIE 2019)

Anais do XXX Simpósio Brasileiro de Informática na Educação (SBIE 2019)

Figure 3. REMAR Platform: Teacher Features

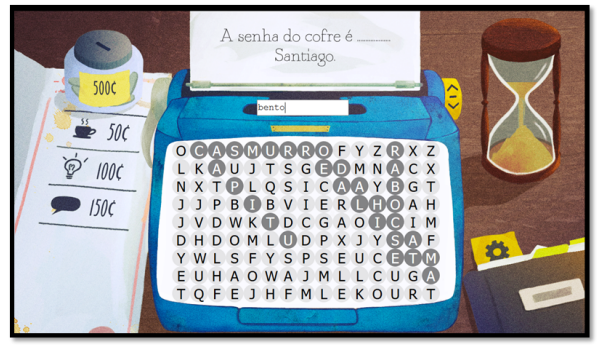

(a) Custom game of the CIA model

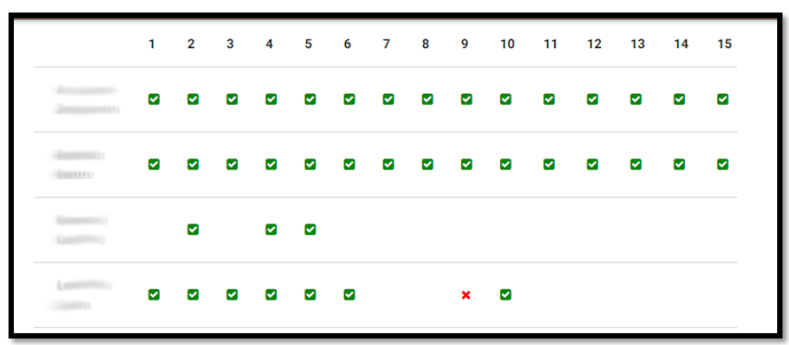

(b) Monitoring students' progress

Source: Image capture from the REMAR platform (CC BY-SA 4.0)

the REMAR platform is integrated with the DSpace ${ }^{5}$ digital repository. In this way, during the customization workflow, the teacher has the following options: (a) cataloging and publication of customization content (question databases, images and so on) as OER under Creative Commons license in the linked DSpace digital repository instance; (b) search of available resources, in the linked DSpace digital repository instance, aiming the reuse of such resources during the game customization workflow (there is a DSpace community for each game model).

4. Group management and monitoring. Teachers can create user groups, manage group participants, share custom games with the group, and track the progress of group participants in shared games. An example of tracking progress (hits and errors) of group members in a custom game instance is illustrated in Figure 3(b). Other information relevant to the monitoring and the best visual representations of them are being currently investigated aiming the subsequent integration into the REMAR platform.

\subsection{REMAR Platform: Student Features}

The following features are available for the student user profile:

1. Access to the platform's game repository (all custom games are public and can be accessed by anyone even if she/he is not a registered user);

2. Access to links (URLs) that provides direct access to the custom games that can be shared by the teachers. Besides it is possible to download the different game instances generated for different platforms (desktop, mobile);

3. Access to user groups and the games shared with the group. You can also track your progress against the group (ranking).

\section{Related Work}

Nogueira, Chaimowicz \& Prates (2013) present Pingo, an online instructional 2D portal with the goal of becoming a repository of multi-disciplinary educational games, allowing preschool and elementary school teachers to customize the content of these games and use them with their students. Content customization takes place through the portal itself where users choose a game and then follows some customization steps to the export of their project.

\footnotetext{
${ }^{5}$ For more details about the DSpace, visit <https://duraspace.org/dspace.>
} 
VIII Congresso Brasileiro de Informática na Educação (CBIE 2019)

Anais do XXX Simpósio Brasileiro de Informática na Educação (SBIE 2019)

Bontchev (2015) provides the example of an educational game called Pro-Enter, a 3D virtual labyrinth in which the player accesses on the walls of the scenarios texts and images referring to concepts of entrepreneurship. This environment still brings two types of mini-games: (a) dynamic quiz (questions and answers) and (b) moving image sequences that need to be sorted. Both mini-games can be customized for a given educational level, allowing educators to insert their own content on the walls of the maze and create their quizzes and picture games.

The analyzed works present solutions for the customization of a game or a specific set of games. The Pingo portal (NOGUEIRA; CHAIMOWICZ; PRATES, 2013) is closer to the REMAR platform conceptual ideas; however, some specific OER issues are not taken into account: (a) construction of versions for different platforms; (b) selection of the adopted Creative Commons open license; and (c) integration with digital repositories (for search and submission of resources during the game customization process).

\section{Evaluation}

This section presents the initial results obtained in the pilot tests involving the platform usage by students, teachers and game developers.

\subsection{User profiles: teachers and students}

In March 2019 some pilots were carried out aiming to evaluate the ease of using the REMAR platform, with the participation of teachers and students from partner institutions. That is, this pilot had the participation of primary, secondary and higher education teachers, as well as undergraduate and specialization students in Education and Technology. The pilot participants were invited to use the REMAR platform and customize some of the available game models. Among the participants, 39 answered a questionnaire that aimed to identify the main difficulties found by them, the positive and negative platform aspects, as well as more specific questions related to the platform user interface and documentation.

Some information about the respondents' profile. About research on educational games, two answers were possible: $74.4 \%$ claims they have already conducted some research on educational games while $25.6 \%$ claims they have not. About experience on game development: (a) $20.5 \%$ claims they have not developed games yet; (b) $74.4 \%$ claims they have not developed games but they would like to; (c) $5.1 \%$ claims they have already developed games. About the educational games usage: (a) 61.5\% claims they have already utilized games; (b) $17.9 \%$ claims they would like to use but it is hard find one that meets their needs; (c) $10.3 \%$ claims they would like to use but do not know where to find them and (d) $10.3 \%$ claims they have not already utilized games.

Some information about the respondents' answers. Regarding the adequacy and sufficiency of the system feedback, on a scale of 1 (totally disagree) to 7 (totally agree), the assessments were: (a) 38.5\% gave grade 7; (b) 17.9\% gave grade 6; (c) $28.2 \%$ gave grade 5; (d) $10.3 \%$ gave grade 4 and (e) $5.1 \%$ gave grade 3 . Regarding the interface consistency, using the 1 to 7 scale, the assessments were: (a) 35.9\% gave grade 7; (b) $30.8 \%$ gave grade 6 ; (c) $25.6 \%$ gave grade 5 ; (d) $5.1 \%$ gave grade 4 and (e) $2.6 \%$ gave grade 1 . And lastly, regarding the plataform usage in their educational practices, three answers were possible: (1) yes (76.9\% of answers); (2) maybe (23.1\% of answers) and (3) no $(0.0 \%$ of answers). 
Among the positive points pointed out, we can cite the main ones: (a) ease of games customization; (b) ease of platform access and usage; (c) flexibility offered to teachers through the games customization; (d) pleasant, intuitive and consistent interface; (e) game instances generation for different platforms; (f) diversity of games and (g) good tutorials.

The negatives were pointed out: (a) lack of guidance for installation on Android devices; (b) inability to edit a customization after the generation of a game instance; (c) lack of games to specific areas (such as Musical Education and early childhood education), as well as some specific bugs identified during the pilot test, but already solved in newer versions of the platform.

\subsection{User profile: game developers}

In 2018 some pilots were carried out aiming to evaluate the ease of developing new game models. During this stage, five game research groups were invited to create customizable game models and integrate them into the REMAR platform.

- Comenius (UFSC). Game that has as a target audience teachers and undergraduate students in pedagogy and aims to help the planning of classes by integrating various types of media. Customizable Items: mission information, divided into: (1) title, description and objectives; and (2) value of choice options (procedures, groupings, spaces and media);

- Líder Sim (UNEB). Game that aims to stimulate the executive functions of university students through simulation and management for planning, execution and monitoring of projects. Customizable items: information, such as description and budget, about projects (problem situations);

- Mar do Saber (USP). Game that invites a dive on the seabed, where the player (diver) collects, by correctly answering quizzes, photos of sea creatures. Customizable Items: Questions (quizzes) and images to be collected;

- Process Legend (UFABC). Game that aims to motivate the learning of computer programming, one of the disciplines with the highest dropout at computing courses. Customizable items: challenges-programming problems that includes the description and expected inputs/outputs of each challenge;

- REJOGO (UFG). It is an interactive digital magazine, which can be customized for different types of games, such as wordplay, puzzles and crosswords. Customizable Items: the interactive digital magazine content.

These groups spent between 2 and 6 months for the game model development (some created the game model based on games already developed by the group while others chose to create new game models from scratch). At the end, five game models were successfully developed and integrated into the platform. The results of this pilot demonstrate the potential platform's growth (maturation) with the integration of new customizable game models developed by different teams.

\section{Concluding Remarks}

By reflecting on the challenges in the development of educational games, we face issues ranging from designing games that actually have the potential to engage students in effective learning processes, in a fun way, going through issues related to inclusive design, 
VIII Congresso Brasileiro de Informática na Educação (CBIE 2019)

Anais do XXX Simpósio Brasileiro de Informática na Educação (SBIE 2019)

which allow access to these resources by people with different limitations. To address these challenges and enable the development and wide usage of high-quality educational games, we advocate the development of these games as open educational resources.

Open access to educational resources is an essential requirement for democratic, quality, sustainable and open education, in any form (face-to-face, distance, hybrid) and at all levels of education. In the case of educational games, pondering the complexity and cost of development, it is imperious that the development community takes into account solutions that favor the collaboration and effective reuse of these resources.

In this article we have presented the REMAR platform, which aims to contribute in this direction, by providing tools for the creation of customized instances of educational games, with open license and in different platforms. In addition to more effective sharing and reuse of educational games, we hope that the REMAR platform can contribute to a culture change by promoting more sustainable and collaborative development of open educational resources.

\section{Acknowledgment}

This study was financed by the Coordenação de Aperfeiçoamento de Pessoal de Nível Superior (CAPES) and Rede Nacional de Pesquisas (RNP) - Brazil.

\section{References}

BONTCHEV, B. Customizable 3D Video Games as Educational Software. In: 7th Int. Conf. on Education and New Learning Technologies. Barcelona, Spain: EDULEARN15, 2015.

CONNOLLY, T. M.; BOYLE, E. A.; MACARTHUR, E.; HAINEY, T.; BOYLE, J. M. A systematic literature review of empirical evidence on computer games and serious games. Computers \& Education, v. 59, n. 2, p. 661-686, 2012.

CSIKSZENTMIHALYI, M. Flow: The Psychology of Optimal Experience. New York, NY: Harper Perennial, 1991.

GEE, J. Good Video Games + Good Learning: Collected Essays on Video Games, Learning, and Literacy. USA: P. Lang, 2007.

KIILI, K.; FREITAS, S. de; ARNAB, S.; LAINEMA, T. The Design Principles for Flow Experience in Educational Games. Procedia Computer Science, v. 15, p. 78-91, 122012.

KLOPFER, E.; OSTERWEIL, S.; SALEN, K. Moving learning games forward. The Education Arcade, Massachusetts Institute of Technology, 2009.

NOGUEIRA, D. N.; CHAIMOWICZ, L.; PRATES, R. O. Pingo - An Online Portal for Educational Games with Customizable Content. In: XV Simpósio Brasileiro de Games e Entretenimento Digital. Brazil: SBC, 2013.

PRENSKY, M. Digital Game-Based Learning. USA: McGraw-Hill, 2000.

STEPHANDI, C. Design for All. In: The Encyclopedia of Human-Computer Interaction. 2nd. ed. USA: Interaction Design Foundation, 2018.

WILEY, D. The Access Compromise and the 5th R. 2019. Available at: <https: //opencontent.org/blog/archives/3221>. Accessed on July 07, 2019. 